\title{
Glycyrrhetic acid (a metabolic substance and aglycon of glycyrrhizin) induces apoptosis in human hepatoma, promyelotic leukemia and stomach cancer cells
}

\author{
HIROSHIGE HIBASAMI $^{1}$, HIROSI IWASE ${ }^{2}$, KAZUMI YOSHIOKA ${ }^{3}$ and HIDEHISA TAKAHASHI ${ }^{2}$ \\ ${ }^{1}$ Faculty of Medicine, Mie University, Tsu-city, Mie 514-0001; ${ }^{2}$ R\&D Cokey Co., Ltd., Tsu-city, Mie 514-0002; \\ ${ }^{3}$ Faculty of Oriental Medicine, Ryotokuji University, Tokyo 120-0000, Japan
}

Received September 7, 2005; Accepted October 10, 2005

\begin{abstract}
We have investigated the effect of glycyrrhetic acid (GR) which is metabolic substance of glycyrrhizin, on DNA of human hepatoma (HLE), promyelotic leukemia (HL-60) and stomach cancer (KATO III) cells. GR displayed apoptotic effects against HLE, HL-60 and KATO III cells. The fragmentation of DNA by GR to oligonucleosomal-sized fragments, a characteristic of apoptosis, was dose- and timedependent in these cell lines. These findings suggest that growth inhibition of these cell lines by GR result from the induction of apoptosis by the compound. Inhibitors of caspases did not suppress the DNA fragmentation caused by GR. N-acetyl-L-cysteine, an antioxidant drug, weakly inhibited the DNA fragmentation caused by GR suggesting that active oxidants work partly as an apoptosis-inducing transfer substance.
\end{abstract}

\section{Introduction}

Thus far we have purified several compounds extracted from plants and evaluated the antitumor activity of these compounds (1-7). The efficiency of the antitumor compounds seems to be related to the propensity of tumor cells to respond to these compounds by apoptosis. Recently, considerable attention has been focused on the sequence of events referred to as apoptosis, and the role of this process in mediating the lethal effects of antineoplastic agents in leukemia cells (8). Apoptosis is a highly regulated process that is characterized by cell shrinkage, membrane blebbing, chromatin condensation and formation of a DNA ladder with multiple fragments of 180200 bp caused by inter-nucleosomal DNA cleavage (9).

Previously we demonstrated induction of apoptosis by phytol (1), sesamin (2), pheophorbide $a$ (3), diol- and triol-

Correspondence to: Dr Hiroshige Hibasami, Faculty of Medicine, Mie University, Tsu-city, Mie 514-0001, Japan

Key words: glycyrrhetic acid, apoptosis, DNA fragmentation, hepatoma, leukemia, stomach cancer cells types of phytol (4), lupeol (5), procyanidin (6) and glycyrrhizin (7) in cultured human lymphoid leukemia and stomach cancer cells.

In the present study, we investigated the effects of glycyrrhetic acid (GR), an aglycon of glycyrrhizin, on DNA of human hepatoma HLE, promyelotic leukemia HL-60 and stomach cancer KATO III, and found induction of apoptotic morphological change of the nucleus resulting from DNA fragmentation in these cell lines.

\section{Materials and methods}

Chemicals. RPMI-1640 and Dulbecco's modified Eagle's medium were purchased from Gibco Laboratories, Grand Island, NY, USA. Lymphocyte separation medium was purchased from ICN Biomedicals Inc., Aurora, OH, USA. GR was purchased from Sigma Chemical Co., St. Louis, MO, USA. The structure of GR is shown in Fig. 1. Inhibitors of caspases were obtained from Peptide Institute, Inc., Osaka, Japan. All other chemicals were of the highest grade available from Nacalai Tesque Inc., Kyoto, Japan.

Cell culture. Human hepatoma HLE cells were cultivated in Dulbecco's modified Eagle's medium with $5 \%$ fetal bovine serum, penicillin $\mathrm{G}(50 \mathrm{IU} / \mathrm{ml})$ and streptomycin $(50 \mu \mathrm{g} / \mathrm{ml})$. Human promyelotic leukemia HL-60 (10) and stomach cancer KATO III (6) were cultivated as previously described. These cells were cultivated at $37^{\circ} \mathrm{C}$ under humidified $95 \%$ air - $5 \% \mathrm{CO}_{2}$ atmosphere. Mycoplasma testing was routinely negative.

Preparation of human lymphocyte cells. Lymphocyte separation medium $(3 \mathrm{ml})$ was aseptically transferred to a centrifuge tube and the diluted blood (heparinized blood: physiological saline $=1: 1$ ) was layered over lymphocyte separation medium in the tube. The tube was centrifuged at $400 \mathrm{x} \mathrm{g}$ at room temperature for $20 \mathrm{~min}$. The top layer of the clear plasma was removed, and the lymphocyte layer was transferred to a new centrifuge tube. An equal volume of PBS(-) was added to the lymphocyte layer in the tube and centrifuged for $10 \mathrm{~min}$ at room temperature at $260 \mathrm{x} \mathrm{g}$. After the centrifugation, the precipitated lymphocyte was washed again with PBS(-), and suspended in RPMI-1640 medium 
<smiles>CC1(C(=O)O)CCC2(C)CCC3(C)C(=CC(=O)[C@H]4C5CCC(O)C(C)(C)C5CCC43C)C2C1</smiles>

Figure 1. Chemical structures of glycyrrhetic acid (GR).

containing $10 \%$ FCS and 2\% phytohemaglutinin-M (Gibco Laboratories). The obtained normal lymphocytes, cells were cultivated in the presence of a vehicle or GR.

Microscopic observation of morphological change of HL-60 cells. Exponentially growing human leukemia HL-60 cells were plated at the initial density of $3-4 \times 10^{5}$ cells $/ \mathrm{ml}$. After cultivating for 3 days in the presence of a vehicle or GR, the cells were fixed with $1 \%$ glutaraldehyde and stained with Hoechst 33258. The morphology of the stained cells was examined by an epifluorescence microscope with a cooled CCD camera digital imaging system and Fuji pictorography 3000 as described by Okumura et al (11).

Assay for DNA fragmentation. Exponentially growing HLE, HL-60 and KATO III cells were plated at $3-4 \times 10^{5}$ cells $/ \mathrm{ml}$. After cultivation in the presence of a vehicle or GR for 1-4 days, the cells were pelleted by centrifugation. DNA was isolated from the cell pellets as described previously (12). Equivalent amounts of DNA $(2 \mu \mathrm{g})$ were loaded into wells of $2 \%$ agarose gel and electrophoresed in $40 \mathrm{mM}$ Tris-acetic acid (pH 7.5) buffer containing 2 mM EDTA.

\section{Results and Discussion}

Induction of apoptosis by GR. The significant growth inhibitory activity of GR led us to investigate whether part of the effects were results of the induction of apoptosis in the human

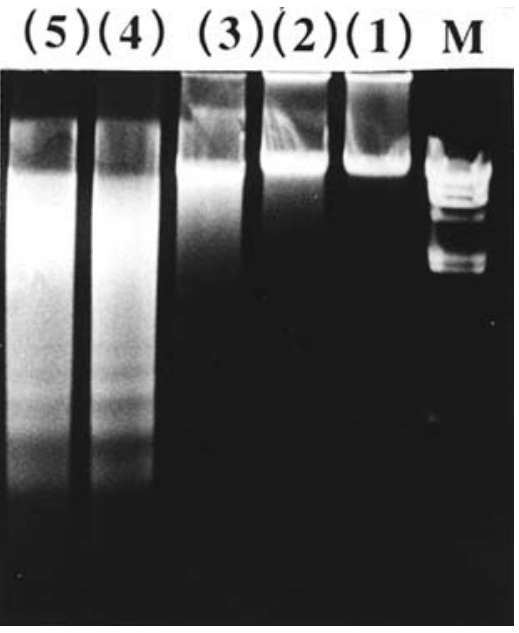

Figure 3. Effects of GR on DNA in the HLE cells. The cells were cultured in the presence of a vehicle (lane 1), 0.25 (lane 2), 0.50 (lane 3), 0.75 (lane 4) and $1.0 \mathrm{mg} / \mathrm{ml}$ (lane 5) GR for 3 days. After the isolation of DNA from the GR-treated cells, equivalent amounts of DNA $(2 \mu \mathrm{g})$ were loaded into wells of $2 \%$ agarose gel and electrophoresed in $40 \mathrm{mM}$ Tris-acetic acid, $\mathrm{pH} 7.5$ containing 2 mM EDTA. M: $\lambda$ DNA digested with HindIII.

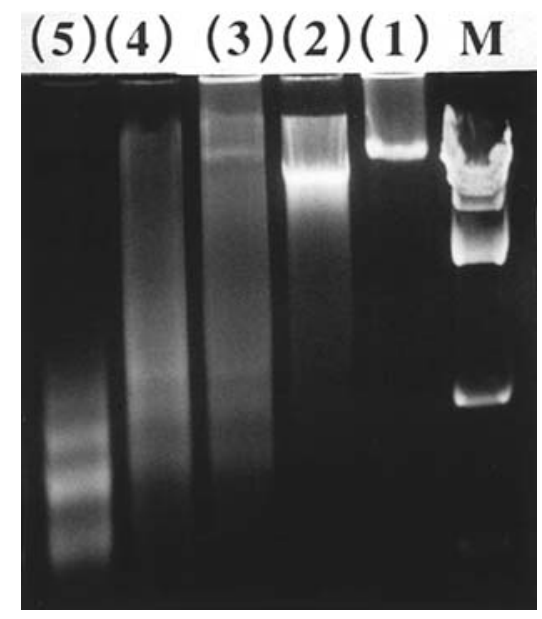

Figure 4. Effects of GR on DNA in the HL-60 cells. The cells were cultivated in the presence of a vehicle (lane 1), 0.1 (lane 2), 0.2 (lane 3), 0.4 (lane 4) and $0.6 \mathrm{mg} / \mathrm{ml}$ (lane 5) GR for 3 days. After the isolation of DNA from the GR-treated cells, equivalent amounts of DNA $(2 \mu \mathrm{g})$ were loaded into wells of $2 \%$ agarose gel and electrophoresed in $40 \mathrm{mM}$ Tris-acetic acid, $\mathrm{pH} 7.5$ containing 2 mM EDTA. M: $\lambda$ DNA digested with HindIII.
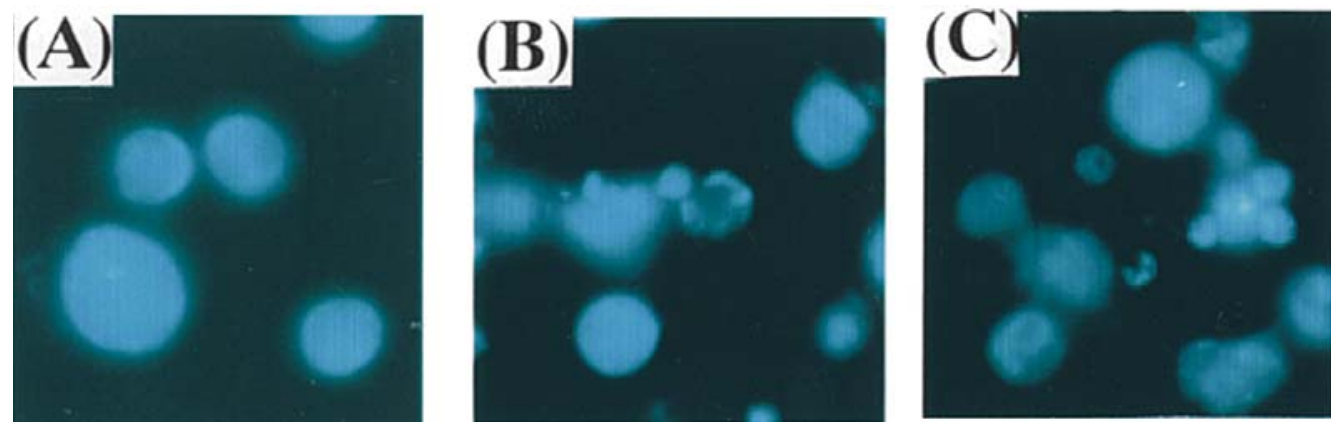

Figure 2. Morphological changes by GR in the HL-60 cells. (A), Non-treated HL-60 cells. (B), HL-60 cells treated with 0.4 mg/ml GR. (C), HL-60 cells treated with $0.6 \mathrm{mg} / \mathrm{ml} \mathrm{GR}$. These cells were cultivated with GR for 3 days, fixed with $1 \%$ glutaraldehyde, stained with Hoechst 33258 , and then observed under an epifluorescence microscope equipped with a cooled CCD camera (phometrics, P x L 1400) digital imaging system and Fuji pictorography 3000. 


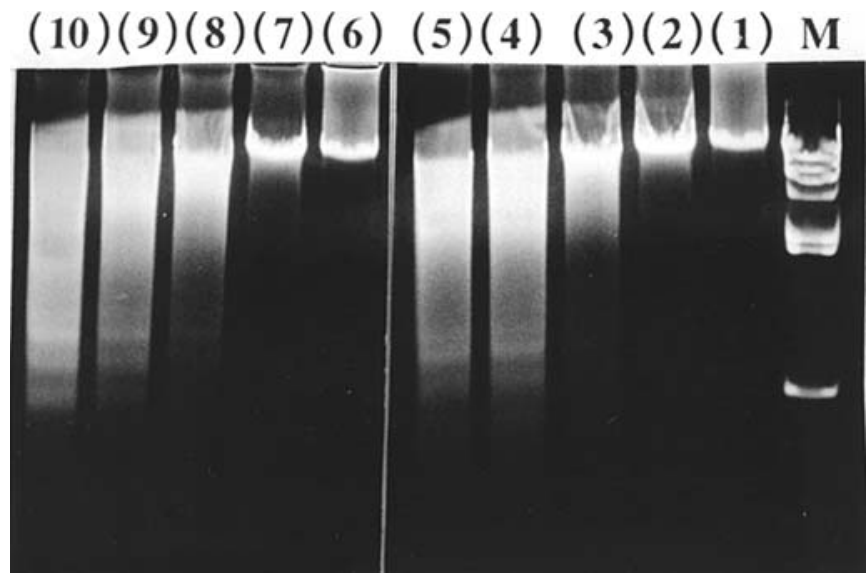

Figure 5. Time-course of DNA fragmentation by GR in the HLE cells. HLE cells were cultivated in the presence of a vehicle (lanes 1 and 6), $0.6 \mathrm{mg} / \mathrm{ml}$ GR (lanes 2-5), $0.7 \mathrm{mg} / \mathrm{ml} \mathrm{GR}$ (lanes 7-10), for 1 day (lanes 2 and 7), 2 days (lanes 3 and 8), 3 days (lanes 4 and 9) and 4 days (lanes 5 and 10). After isolation of DNA from the GR-treated cells, equivalent amounts of DNA $(2 \mu \mathrm{g})$ were loaded into wells of $2 \%$ agarose gel and electrophoresed in $40 \mathrm{mM}$ Tris-acetic acid, pH 7.5 containing 2 mM EDTA. M: $\lambda$ DNA digested with HindIII.

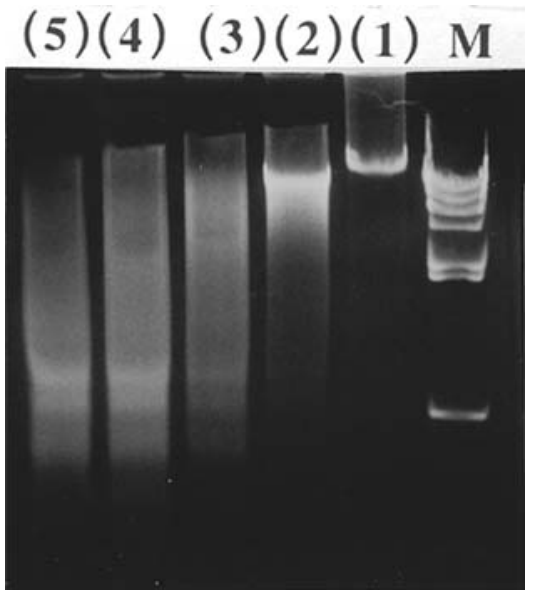

Figure 6. Time-course of DNA fragmentation by GR in the HL-60 cells. HL-60 cells were cultivated in the presence of a vehicle (lane 1), $0.4 \mathrm{mg} / \mathrm{ml}$ GR (lanes 2-5), for 1 day (lane 2), 2 days (lane 3), 3 days (lane 4) and 4 days (lane 5). After isolation of DNA from the GR-treated cells, equivalent amounts of DNA $(2 \mu \mathrm{g})$ were loaded into wells of $2 \%$ agarose gel and electrophoresed in $40 \mathrm{mM}$ Tris-acetic acid, $\mathrm{pH} 7.5$ containing 2 mM EDTA. M: $\lambda$ DNA digested with HindIII.

hepatoma (HLE), promyelotic leukemia (HL-60) and stomach cancer (KATO III) cells. Morphological change showing apoptotic body and fragmentation of genomic DNA into oligonucleosomal-sized fragments (DNA ladder) are characteristics of the occurrence of apoptosis. The morphology of HL-60 cells showed apoptotic bodies after 3 days of treatment with 0.4-0.6 mg/ml GR (Fig. 2).

DNA ladders were observed in the HLE cells treated with $0.75-1.0 \mathrm{mg} / \mathrm{ml} \mathrm{GR}$ (Fig. 3) and in the HL-60 cells treated with $0.2-0.6 \mathrm{mg} / \mathrm{ml}$ (Fig. 4). DNA fragmentation occurred by the lower concentration of GR in the HL-60 cells than that in the HLE cells.

In the time-course experiments, the amounts of the DNA fragments in the GR-treated HLE (Fig. 5) and HL-60 (Fig. 6)

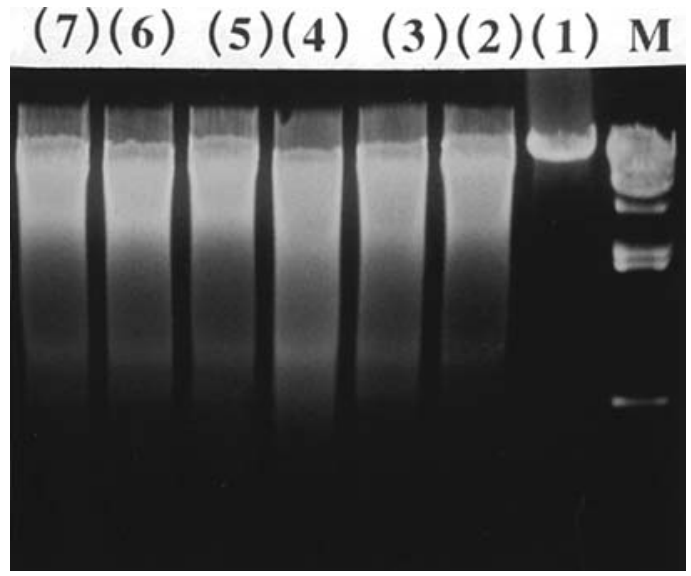

Figure 7. Effects of various caspase inhibitors on DNA fragmentation caused the addition of $0.8 \mathrm{mg} / \mathrm{ml} \mathrm{GR}$ (lanes 2-7) to the HLE cells pre-treated with DMSO (solvent of caspase inhibitor) (lane 2), $100 \mu \mathrm{M}$ Ac-DEVD-CHO (lane 3), Z-VAD-FMK (lane 4), Z-Asp-CH2-DCB (lane 5), Ac-DMOD-CHO (lane 6) and Ac-IETD-CHO (lane 7). After the incubation for 3 days, DNA was isolated from the treated cells, equivalent amounts of DNA $(2 \mu \mathrm{g})$ were loaded into wells of $2 \%$ agarose gel and electrophoresed in $40 \mathrm{mM}$ Tris-acetic acid, pH 7.5 containing 2 mM EDTA. M: גDNA digested with HindIII.

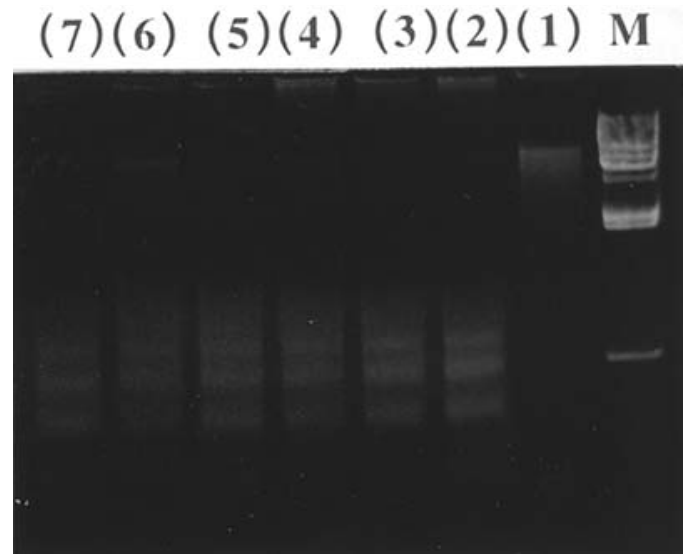

Figure 8. Effects of various caspase inhibitors on DNA fragmentation caused the addition of $0.6 \mathrm{mg} / \mathrm{ml} \mathrm{GR}$ (lanes 2-7) to the KATO III cells pre-treated with DMSO (solvent of caspase inhibitor) (lane 2), $100 \mu \mathrm{M}$ Ac-DEVD-CHO (lane 3), Z-VAD-FMK (lane 4), Z-Asp-CH2-DCB (lane 5), Ac-DMOD-CHO (lane 6) and Ac-IETD-CHO (lane 7). After the incubation for 3 days, DNA was isolated from the treated cells, equivalent amounts of DNA $(2 \mu \mathrm{g})$ were loaded into wells of $2 \%$ agarose gel and electrophoresed in $40 \mathrm{mM}$ Tris-acetic acid, pH 7.5 containing 2 mM EDTA. M: גDNA digested with HindIII.

cells increased in a time-dependent manner. Based on these findings, it is considered that growth inhibitions of these cells by GR are caused by induction of apoptosis.

Mechanism of apoptosis induced by GR. The mechanism of apoptosis induction by GR was investigated. In this study, caspase inhibitors, Ac-DEVD-CHO, Z-VAD-FMK, Z-AspCH2-DCB, Ac-DMOD-CHO and Ac-IETD-CHO did not suppress DNA fragmentation by GR in the HLE cells (Fig. 7) and KATO III cells (Fig. 8). These findings indicate that the induction of apoptosis by GR may be primarily mediated through other caspases. Such possibilities will need to be investigated in the future. On the other hand, apoptosisinduction by non-dependent caspase cascade process has 


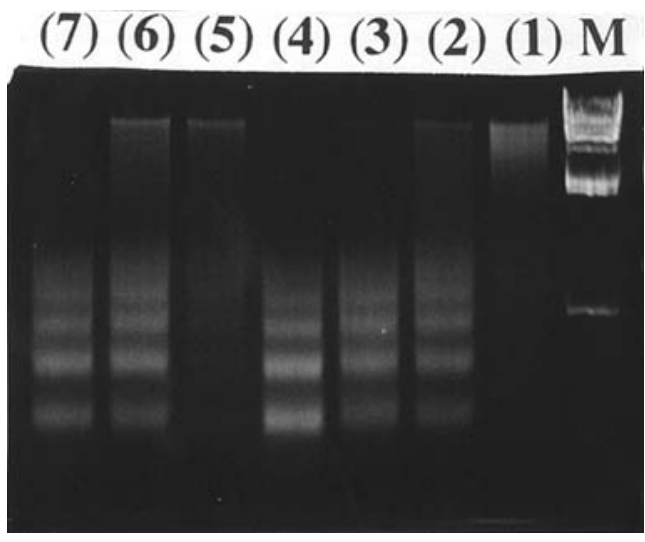

Figure 9. Effect of N-acetyl-L-cysteine, an antioxidant drug, on DNA fragmentation caused by the addition of 0.4 (lanes 2 and 5), 0.6 (lanes 3 and 6) and $0.8 \mathrm{mg} / \mathrm{ml}$ (lanes 4 and 7) GR to the KATO III cells pre-treated with $5 \mathrm{mM}$ $\mathrm{N}$-acetyl-L-cysteine (lanes 5-7). After the incubation for 3 days, DNA was isolated from the treated cells, equivalent amounts of DNA $(2 \mu \mathrm{g})$ were loaded into wells of $2 \%$ agarose gel and electrophoresed in $40 \mathrm{mM}$ Tris-acetic acid, pH 7.5 containing 2 mM EDTA. M: $\lambda$ DNA digested with HindIII.

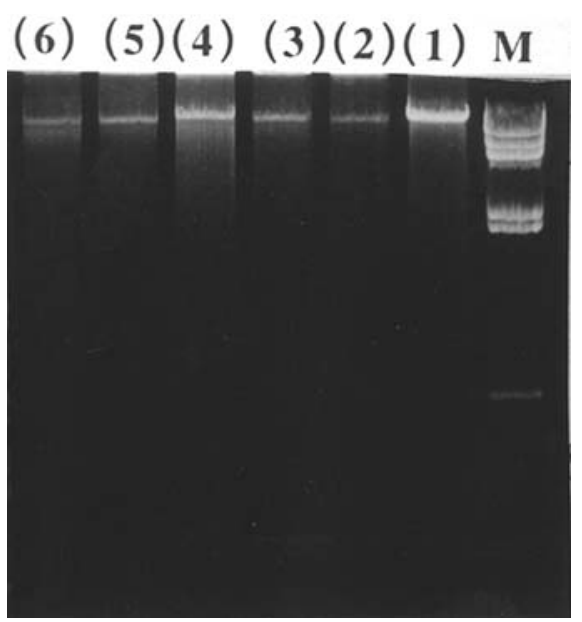

Figure 10. Effect of GR on normal lymphocyte cells. The cells were cultivated in the presence of a vehicle (lane 1), 0.2 (lane 2), 0.4 (lane 3), 0.6 (lane 4), 0.8 (lane 5) and $1.0 \mathrm{mg} / \mathrm{ml}$ (lane 6) GR for 3 days. After isolation of DNA from the GR-treated cells, equivalent amounts of DNA $(2 \mu \mathrm{g})$ were loaded into wells of $2 \%$ agarose gel and electrophoresed in $40 \mathrm{mM}$ Tris-acetic acid, pH 7.5 containing 2 mM EDTA. M: גDNA digested with HindIII.

been reported by Susin et al (13). According to their report, membrane potential of the mitochondria falls and an apoptosis-inducing factor is produced. This apoptosisinducing factor supposes that apoptosis is induced under the existence of caspase inhibitors. From this it is possible to surmise whether to continue the course in which apoptosisinducing factors participate in apoptosis induced by GR.

Active oxidants are reported to be a factor responsible for altering the characteristics of the mitochondria membrane (14). Shimura et al (15) reported on the emittance of apoptosis-inducing factors. They showed that active oxidant was an important factor in apoptosis induction through the non-dependent caspase cascade.

In this study it was believed that the active oxidants would work as an apoptosis-inducing signal transfer substance. The active oxidants were attacked by the addition of N-acetyl-Lcysteine, an antioxidant, for 3 days. It was found that $\mathrm{N}$-acetylL-cysteine weakly suppressed the DNA fragmentations induced by GR (Fig. 9). These findings suggest that growth inhibition of KATO III cells caused by GR results from the induction of apoptosis caused by the compound by weak involvement of active oxygen and other unknown mechanisms.

In contrast we observed no induction of apoptosis by GR in normal leukocytes prepared from healthy volunteers (Fig. 10). Non-cancerous lymphocytes prepared from healthy volunteers were not affected by GR, suggesting that the activity of this compound is specific for cancer cells and would not be destructive to healthy tissues.

In general, during apoptosis several characteristic morphological changes are induced, both in the cytoskeleton (leading to bleb formation) and in the nucleus (chromatin condensation and nuclear fragmentation). Recently, it was shown that upon apoptosis, stimulus substance decreases and mitochondria factors (cytochrome $\mathrm{C}$ and apoptosis-inducing factor) are released from the mitochondria $(16,17)$. Also characteristic of apoptosis is the involvement of phosphatidyl serine on the extracellular side of the plasma membrane and activation of caspase.

In conclusion, these findings demonstrate that GR might exert antitumor activity by triggering apoptosis in the human hepatoma HLE, promyelotic leukemia HL-60 and stomach cancer KATO III cells. A strategy to selectively induce apoptosis of hepatoma, stomach cancer and leukemic cells without altering healthy cells is a major goal for the development of new therapeutic techniques.

\section{References}

1. Komiya T, Achiwa Y, Katsuzaki H, Imai K and Hibasami H: Phytol induces programmed cell death in human lymphoid leukemia Molt 4B cells. Int J Mol Med 4: 377-380, 1999.

2. Miyahara Y, Komiya T, Katsuzaki H, Imai K, Nakagawa M, Ishii $\mathrm{Y}$ and Hibasami $\mathrm{H}$ : Sesamin and episesamin induce apoptosis in human lymphoid leukemia Molt 4B cells. Int J Mol Med 6: 43-46, 2000

3. Hibasami H, Kyokon M, Ohwaki S, Katsuzaki H, Imai K, Nakagawa M, Ishii Y and Komiya T: Pheophorbide a, a moiety of chlorophyll a, induces apoptosis in human lymphoid leukemia Molt 4B cells. Int J Mol Med 6: 277-279, 2000.

4. Hibasami H, Kyokon M, Ohwaki S and Komiya T: Diol- and triol-types of phytol induce apoptosis in lymphoid leukemia Molt 4B cells. Int J Mol Med 10: 555-559, 2002.

5. Aratanechemuge Y, Hibasami H, Sanpin K, Katsuzaki H, Imai K and Komiya T: Induction of apoptosis by lupeol isolated mokumen (Gossampinus malabarica L. Merr) in human promyelotic leukemia HL-60 cells. Oncol Rep 11: 289-292, 2004.

6. Hibasami H, Shohji T, Shibuya I, Higo K and Kanda T: Induction of apoptosis by three types of procyanidin isolated from apple in human stomach cancer KATO III cells. Int J Mol Med 13: 795-799, 2004.

7. Hibasami H, Iwase H, Yoshioka K and Takahashi H: Glycyrrhizin induces apoptosis in human stomach cancer KATO III and human promyelotic leukemia HL-60 cells. Int J Mol Med 16: 233-236, 2005 .

8. Kaufman SN: Induction by endonucleolytic DNA cleavage in human acute myelogenous leukemia by etoposide, camptothecin and other cytotoxic anticancer drugs: a cautionary note. Cancer Res 49: 5870-5878, 1989.

9. Steller H: Mechanisms and genes of cellular suicide. Science 267: 1445-1449, 1995.

10. Moteki H, Hibasami H, Yamada Y, Katsuzaki H, Imai K and Komiya T: Specific induction of apoptosis by 1,8-cineole in two human leukemia cell lines, but not in a human stomach cancer cell line. Oncol Rep 9: 757-760, 2002. 
11. Okumura K, Nogami M, Taguchi H, Hisamatsu H and Tanaka K: The genes for the $\theta$-type HC3 and B-type HC5 subunits of human proteasome map to chromosomes $6 \mathrm{q} 27$ and $7 \mathrm{q} 12$-p13 by fluorescence in situ hybridization. Genomics 27: 377-379, 1995.

12. Mori K, Hibasami H, Satoh N, Sonoda J, Uchida A and Nakashima K: Induction of apoptotic cell death in three human osteosarcoma cell lines by a polyamine synthesis inhibitor, methyl-glyoxal bis(cyclopentylamidinohydrazone) (MGBCP). Anticancer Res 17: 2390-2395, 1997.

13. Susin SA, Lorenzo HK, Zamzami N, Marzo I, Snow BE, Penninger JM and Kroemer G: Molecular characterization of mitochondrial apoptosis-inducing factor. Nature 397: 441-446, 1999.

14. Lotem J, Peled-Kaman M, Groner Y and Sachs L: Cellular oxidative stress and the control of apoptosis by wild-type p53, cytotoxic compounds and cytotoxins. Proc Natl Acad Sci USA 93: 9166-9171, 1996.
15. Shimura M, Osawa Y, You A, Hatake K, Takaku F and Ishizuka Y: Oxidative stress as a necessary factor in room temperature-induced apoptosis of HL-60 cells. J Leukoc Biol 68: 87-95, 2000

16. Kluck RM, Boossy-Wetzel E, Green DR and Newmeyer DD: The release of cytochrome $\mathrm{C}$ from mitochondria. A primary site for Bcl-2 regulation of apoptosis. Science 275: 1132-1136, 1997.

17. Susin SA, Zamzami N, Castero M, Hirsch T, Marchetti P, Macho A, Gaugas E, Geuskens M and Kroemer G: Bcl-2 inhibits the mito-chondrial release of an apoptogenic protease. J Exp Med 184: 1331-1341, 1996. 